\title{
Use of Monoclonal Antibodies in the Sensitive Detection and Neutralization of Botulinum Neurotoxin Serotype B
}

\author{
Luisa W. Cheng ${ }^{1, *}$, Thomas D. Henderson II ${ }^{1}$, Tina I. Lam ${ }^{2}$ and Larry H. Stanker ${ }^{1}$ \\ Received: 30 September 2015; Accepted: 12 November 2015; Published: 27 November 2015 \\ Academic Editors: Xiaohua He and Vernon Tesh \\ 1 Foodborne Toxin Detection and Prevention Research Unit, Western Regional Research Center, \\ Agricultural Research Service, United States Department of Agriculture, Albany, CA 94710, USA; \\ thomas.henderson@ars.usda.gov (T.D.H.); larry.stanker@ars.usda.gov (L.H.S.) \\ 2 Gilead Sciences, Inc., Foster City, CA 94404, USA; tinaiunsanlam@gmail.com \\ * Correspondence: luisa.cheng@ars.usda.gov; Tel.: +1-510-559-6337; Fax: +1-510-559-5880
}

\begin{abstract}
Botulinum neurotoxins (BoNT) are some of nature's most potent toxins. Due to potential food contamination, and bioterrorism concerns, the development of detection reagents, therapeutics and countermeasures are of urgent interest. Recently, we have developed a sensitive electrochemiluminescent (ECL) immunoassay for BoNT/B, using monoclonal antibodies (mAbs) MCS6-27 and anti-BoNT/B rabbit polyclonal antibodies as the capture and detector. The ECL assay detected as little as $1 \mathrm{pg} / \mathrm{mL}$ BoNT/B in the buffer matrix, surpassing the detection sensitivities of the gold standard mouse bioassays. The ECL assay also allowed detection of BoNT/B in sera matrices of up to $100 \%$ sera with negligible matrix effects. This highly-sensitive assay allowed the determination of the biological half-lives of BoNT/B holotoxin in vivo. We further tested the toxin neutralization potential of our monoclonal antibodies using the mouse systemic and oral intoxication models. A combination of mAbs protected mice in both pre- and post-exposure models to lethal doses of BoNT/B. MAbs were capable of increasing survival of animals when administered even $10 \mathrm{~h}$ post-intoxication in an oral model, suggesting a likely time for BoNT/B complexes to reach the blood stream. More sensitive detection assays and treatments against BoNT intoxication will greatly enhance efforts to combat botulism.
\end{abstract}

Keywords: monoclonal antibodies; mouse models; botulinum neurotoxins; toxin neutralization; toxicokinetics

\section{Introduction}

Botulinum neurotoxins (BoNT) are some of the most potent natural toxins [1-3]. BoNTs are 150-kDa toxins produced by Clostridium botulinum, C. butyricum, and C. baratii [4-6]. BoNTs consists of a 100-kDa heavy chain (Hc) and a 50-kDa light chain (Lc). The 50-kDa Lc contains the endopeptidase catalytic domain that targets the soluble $N$-ethylmaleimide sensitive factor attachment protein receptor (SNARE) proteins and vesicle-associated membrane protein (VAMP/synaptobrevin) $[3,7]$. For example, synaptobrevin-II is the target for BoNT/B. Cleavage of either SNARE or VAMP proteins results in the inhibition of neurotransmitter release, leading to paralysis. The BoNT Hc contains the receptor binding and translocation domains that allow the toxin to be taken up by neurons [8,9]. BoNT holotoxins associate with neurotoxin-associated proteins (NAP) to form large toxin complexes. NAPs have been shown to provide protection from digestion and help promote BoNT intestinal binding and internalization [10,11]. 
Intoxication with BoNTs, either through ingestion of contaminated food, injection drug use, or through the environment, leads to the illness called botulism. In severe botulism cases, patients often require intensive care with mechanical ventilation. The therapeutics available are equine antitoxins and the Botulinum immunoglobulin (BabyBIG ${ }^{\circledR}$ ) human antibody for use in infant botulism cases $[1,12,13]$. However, equine antitoxins could cause serious side effects, such as serum sickness and anaphylaxis; and the availability of BabyBIG ${ }^{\circledR}$ is limited $[14,15]$. Neutralizing antibodies must also be administered early on during the course of intoxication, presumably before toxin is absorbed onto neurons, to be effective. Thus, there is a strong need for better and faster detection methods, and renewable and safe sources of neutralizing antibodies against BoNTs.

In order to accurately diagnose botulism, many tests on biological samples are performed. The gold standard for the detection of BoNTs is the mouse bioassay. The output for this assay is the death of at least two animals administered toxins, and the BoNT serotype involved is subsequently identified with antibody neutralization [16,17]. However, animal bioassays take at least $72 \mathrm{~h}$ to perform and require the use of animals. Therefore, several detection assays, usually immunoassay-based, are performed for quick confirmatory purposes. We have previously described the development of high affinity monoclonal antibodies (mAbs), MCS6-27 (against the Hc) and BoB92-32-1-10 (BoB92-32 in short, against the Hc [18-21]. These mAbs were used successfully in electrochemiluminescence (ECL) detection assays for BoNT/B in complex food matrices with limits of detection of $13 \mathrm{pg} / \mathrm{mL}$ [20]. Using these very sensitive methods, one can determine the toxicokinetics of BoNT in vivo [22].

In this study, we report the further optimization of the ECL assay using rabbit polyclonal anti-BoNT/B antibodies as the secondary detector. Using this improved method, the toxin levels in mouse sera over time were determined and compared with the timing of $\mathrm{mAb}$ rescue post-intoxication. We also determined the in vivo neutralization potential of single and combinatorial BoNT/B mAbs in systemic and oral models of botulism. The effects of antibody dosage and the timing of neutralizing antibody administration were tested. Increased knowledge of the in vivo half-lives of toxins, improved detection methods, and the identification of efficacious neutralizing antibodies will help advance treatments for botulism.

\section{Results and Discussion}

\subsection{Detection of BoNT/B Using Electrochemiluminescent (ECL) Immunoassay}

The gold standard for detection of BoNTs employs the mouse bioassay. The mouse bioassay can detect BoNT/B levels of $25 \mathrm{pg} / \mathrm{mL}[13,20,23]$. However, these assays require about 3-4 days for full confirmation. To improve detection sensitivity and speed, we have previously described the development of high affinity monoclonal antibodies (mAbs), MCS6-27 and BoB92-32, and their use in ELISA detection of BoNT/B $[19,21]$. Both of these $m A b s$ were against the Hc receptor binding domain (E859-E1291) of BoNT/B and were used successfully in electrochemiluminescence (ECL) detection assays in complex food matrices and horse sera [20]. Limits of detection for BoNT/B in buffer conditions were as low as $13 \mathrm{pg} / \mathrm{mL}$. The ECL assays, like ELISA type immunoassays, take about $4-5 \mathrm{~h}$ to complete, but are less sensitive to food matrix effects. In addition, less sample volume is needed $(15 \mu \mathrm{L}$ vs. $50-100 \mu \mathrm{L})$ than an ELISA or animal bioassay.

Mice are highly sensitive to BoNT toxins. The $\mathrm{LD}_{50}$ for BoNT/B is about $12.5 \mathrm{pg}$ for a $20 \mathrm{~g}$ mouse [20]. In order to determine the biologic half-life of BoNT/B holotoxins in mice, assays need to be able to detect low picogram amounts of BoNT/B in complex matrices, such as sera. To improve the sensitivity of the ECL assay, we tested the use of a rabbit polyclonal anti-BoNT/B antibody coupled with goat anti-Rabbit detector (SULFO-TAG labeled). We improved the limit of detection (LOD) for BoNT/B to $1 \pm 0.1 \mathrm{pg} / \mathrm{mL}$ with a dynamic range for standard detection from $0.5 \mathrm{pg} / \mathrm{mL}$ to $100 \mathrm{ng} / \mathrm{mL}$ in buffer conditions (Figure 1A). Using this assay, we also tested the effect of fresh mouse sera matrix on detection sensitivity. Use of $50 \%, 75 \%$, or $100 \%$ sera had negligible effects 
on detection sensitivity compared to the buffer matrix (Figure 1B). We believe the polyclonal rabbit antibodies contained multiple antibodies binding to different epitopes of captured BoNT/B; this, in turn, improved detection sensitivity. An improvement on detection sensitivity was also observed when multiple mAbs were used as detector antibodies in ELISA assays (data not shown).

We used this sensitive ECL assay to determine the biological half-lives of BoNT/B after intravenous (IV) introduction of toxin. Random sets of five mice were treated with $1000 \mathrm{pg}$ BoNT/B holotoxin (about 80 mouse $\mathrm{LD}_{50}$ ) via tail vein IV injection. Sera were collected from each set of mice over time and the levels of BoNT/B were determined using the Meso Scale Discovery (MSD) instrument. Sera concentrations of BoNT/B over $3 \mathrm{~h}$ were then plotted (Figure 2). Soon after injection, BoNT/B holotoxin levels declined rapidly within the first 10 min of toxin introduction followed by a slower rate of toxin decline in the bloodstream. This initial phase or alpha half-life $\left(t_{1 / 2} \alpha\right)$ was determined to be $2.3 \mathrm{~min}$ and represented the period of toxin redistribution to tissues, extracellular spaces and uptake by neurons (Figure 2). The second phase or $t_{1 / 2} \beta$ half-life was determined to be $105 \mathrm{~min}$ and likely represented the natural clearance of BoNT from the blood.
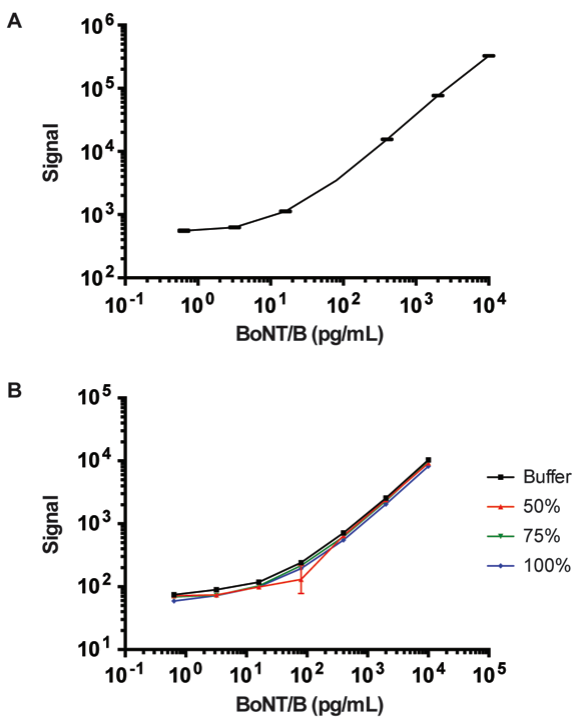

Figure 1. Electrochemiluminescent detection of BoNT/B with a MSD instrument. (A) Diagram of serial 1:5 dilutions of BoNT/B with a range of 10,000 to $0.64 \mathrm{pg} / \mathrm{mL}$ detected using an ECL assay using anti-BoNT/B mAb MCS6-27 for capture, and SULFO-TAG-labeled rabbit anti-BoNT/B polyclonal antibody for detection; and (B) the detection of BoNT/B dilution standards in the presence of buffer only or $50 \%, 75 \%$, or $100 \%$ sera were compared. Graph points showed the mean \pm SEM of duplicate wells.

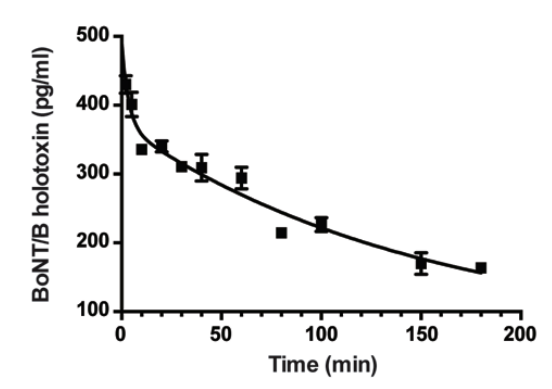

Figure 2. In vivo biological half-live of BoNT/B. Groups of five mice were injected with $1000 \mathrm{pg} /$ mouse of BoNT/B and sera were obtained at 5, 10, 20, 30, 40, 80, 120, and $160 \mathrm{~min}$ post-intoxication. The concentration of unknown BoNT/B was determined using the ECL method. Each data point in graph represents the mean \pm S.E.M. $R^{2}=0.8937$. 
The serum half-life for BoNT/B was comparably faster than to those measured for BoNT/B in rats using radiolabeling [24]. This could be due to differences in toxin uptake in these two animals. Rats are not as susceptible to BoNT/B intoxication as mice due to differences in toxin receptors $[25,26]$.

\subsection{Neutralization of BoNT/B with Monoclonal Antibodies}

We tested the neutralization potencies of individual and combinations of mAbs against BoNT/B in both the IV and oral mouse models of botulism. Three mAbs, MCS6-27, BoB92-23, and BoB92-32, all specific against the Hc receptor binding domain (amino acids E859-E1291) of BoNT/B were used alone or in combination to treat mice dosed with lethal doses of BoNT/B. These mAbs were first chosen because of their binding activity in BoNT/B capture assays. First, mice were administered different doses of mAbs by IV 30 min before injection with $1000 \mathrm{pg} /$ mouse or about 80 mouse IV $\mathrm{LD}_{50}$ of BoNT holotoxin. Mice pre-treated with $10 \mu \mathrm{g}$ of MCS6-27 or $0.4 \mu \mathrm{g}$ BoB92-23, or $50 \mu \mathrm{g}$ BoB92-32 prior to BoNT/B injection, were completely protected from death (Figure 3A-C). Control mice treated with PBS alone died with a median survival time of $6 \mathrm{~h}$. Treatment with $0.4 \mu \mathrm{g}$ MCS6-27, $0.08 \mu \mathrm{g}$ BoB92-23, or $2 \mu \mathrm{g}$ BoB92-32 only led to a slight delay in median survival time to 18,14 , and $14 \mathrm{~h}$, respectively (Figure $3 \mathrm{~A}-\mathrm{C}$ ). In contrast, treatment with $2.5 \mu \mathrm{g}$ of a combination of these same concentrations of mAbs (from here referred as Combo mAbs: $0.4 \mu \mathrm{g}$ MCS6-27, $0.08 \mu \mathrm{g}$ BoB92-23, and $2 \mu \mathrm{g}$ BoB92-32) conferred complete protection from death (Figure 3D).

A

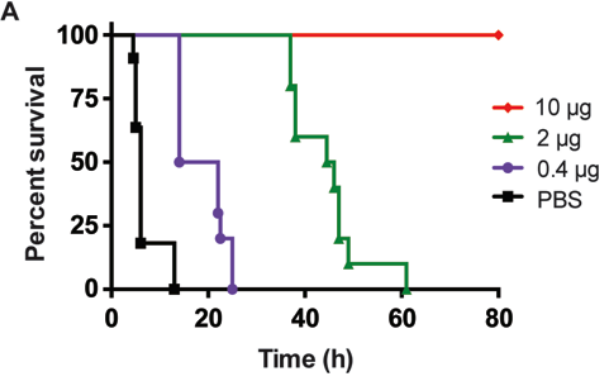

C

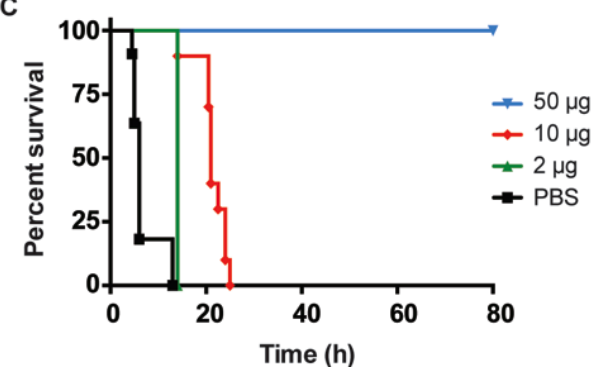

B

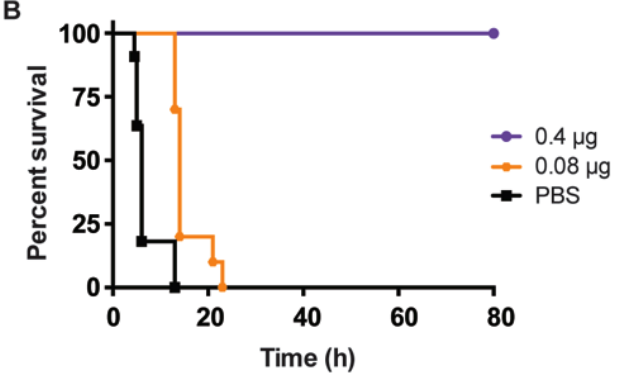

D

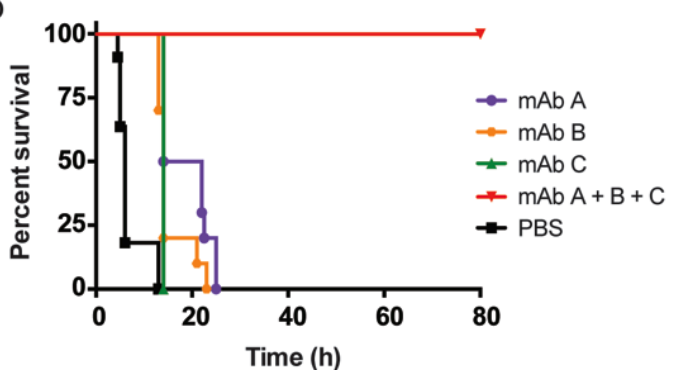

Figure 3. Monoclonal antibody neutralization of BoNT/B in the intravenous mouse model. The percent survival of mice treated with different doses of MCS6-27 (A); BoB92-23 (B); BoB92-32 (C); or Combo mAbs, containing 0.4 $\mu \mathrm{g}$ MCS6-27, $0.08 \mu \mathrm{g}$ BoB92-23, and $2 \mu \mathrm{g}$ BoB92-32 mAbs (D) one hour prior to challenge with BoNT/B were plotted over time. The percent survival of individual mAbs present in the Combo was also plotted for comparison. Control mice were treated with PBS iv instead of $\mathrm{mAbs}$ before intoxication.

Neutralization of BoNT/B with high doses of individual mAbs (such as $10 \mu \mathrm{g}$ MCS6-27, $0.4 \mu \mathrm{g}$ of BoB92-23, and $50 \mu \mathrm{g}$ of 92-32) can fully protect mice from toxin lethality, but as reported by others, a combination of $m A b s$ against different binding sites of BoNT had a synergistic effect on neutralization potential [27]. A combination of three single mAbs (Figure 3D) at much lower mAb concentrations can protect better, presumably because $\mathrm{mAb}$ binding at multiple toxin sites enables steric hindrance of receptor binding and also presumably by enhancing Fc domain binding and eventually immune 
clearance of toxins from blood. Previous studies have found that most BoNTs were cleared into the liver and not found associated with non-immune organs [24,28].

We wanted to determine the time frames when mAbs can rescue mice from death or delay the time-to-death. This information will help us understand whether there are windows of opportunity for treatment and would also give us clues to the timing of toxin passage in the mouse intestinal tract. Mice were treated IV with $1000 \mathrm{pg}$ of BoNT/B holotoxin. A $12.4 \mu \mathrm{g}$ dose of Combo mAbs (2 $\mu \mathrm{g} 6-27$, $0.4 \mu \mathrm{g} 92-23$ and $10 \mu \mathrm{g}$ 92-32) was then administered IV 5, 10, 15, 20, and $40 \mathrm{~min}$ post-intoxication. This dose, five times the dose used for complete protection of mice in Figure 3D, was chosen to ensure complete protection from intoxication. At this dose, toxin that is not neuron or tissue bound would be cleared from the system. Treatment with Combo mAbs 10 min or less after intoxication completely rescued mice from death (Figure 4). A time-to-death delay was seen when mice were given Combo mAbs 15 min post-intoxication with a median survival time of $60 \mathrm{~h}$. Mice treated $20 \mathrm{~min}$ or more post-intoxication showed only a slight delay of time-to-death when compared with PBS-treated mice with median survival times of 14 and $4.5 \mathrm{~h}$, respectively (Figure 4). This method helps predict the timing of when toxin is absorbed by neurons or tissues. At later time points, lethal amounts of BoNT/B would have been taken up and $\mathrm{mAb}$ neutralization would not prolong survival.

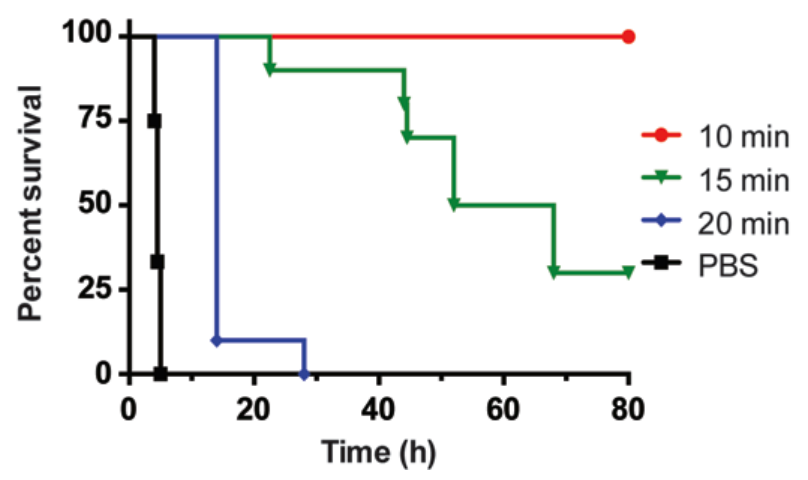

Figure 4. Neutralization of BoNT/B after intravenous intoxication. The percent survival of groups of 10 mice challenged iv with $1000 \mathrm{pg}$ of BoNT/B holotoxin followed by treatment with PBS or $12.4 \mu \mathrm{g}$ of Combo mAbs at 10, 15, and 20 min post-intoxication were plotted over time.

Both the half-life data and the post-IV intoxication $\mathrm{mAb}$ neutralization results indicate that once BoNT/B enters the blood stream, the window of time to neutralize toxins is short. The remaining BoNT/B that is not absorbed into neurons in the sera is slowly cleared. This remaining toxin reservoir is the target of current antitoxin therapies. For most foodborne cases of botulism, equine antitoxin therapy is recommended as early as possible after toxin confirmation. Positive treatment outcomes are directly correlated with early administration of antitoxins [1,14].

Compared to systemic intoxication, relatively large amounts of BoNT must be present to cause disease after oral ingestion [11,18]. Most of the BoNTs are likely degraded in the intestinal tract or shed as waste, with very little actually absorbed by the animal. Previous research showed that the BoNT/A complex was 17 times more toxic than BoNT/A holotoxin in the oral route of intoxication. This is likely due to protection from degradation of the botulinum toxin in the acidic environment and neurotoxin-associated proteins (NAP) mediated entry $[10,11]$. Although BoNT/A and BoNT/B complex have similar neurotoxin-associated protein (NAP) compositions, BoNT/B has been observed to form larger complexes than BoNT/A complexes in native gels [29]. BoNT/B complexes are also about $100 \times$ more toxic than BoNT/A complexes in oral intoxications of mice.

In this study, we tested the neutralization of BoNT/B complex in the oral mouse model of intoxication. Mice were treated with $0.06 \mu \mathrm{g}$ or about three oral $\mathrm{LD}_{50}$ of BoNT/B complex by gavage, followed by IV injection with $12.4 \mu \mathrm{g}$ of Combo mAbs at (Figure 5). Intravenous injection of Combo mAb within $8 \mathrm{~h}$ conferred complete protection (defined as no lethality among treated mice). 
Treatment with the same dose of Combo mAb at $10 \mathrm{~h}$ post-intoxication reduced mortality to $20 \%$ and mice treated with Combo mAbs at $12 \mathrm{~h}$ had $80 \%$ lethality with a median survival of $32 \mathrm{~h}$ (Figure 5). Mice that survive toxin or antibody treatment will recover completely over time. Control mice treated with PBS at $6 \mathrm{~h}$ post-intoxication had a median survival of $26 \mathrm{~h}$.

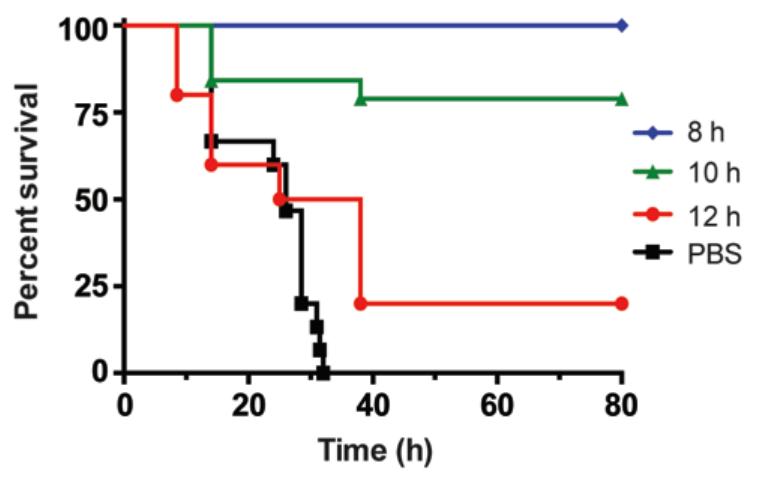

Figure 5. Neutralization of BoNT/B after oral intoxication. The percent survival of groups of 10 mice administered $0.06 \mu \mathrm{g}$ or about three mouse oral $\mathrm{LD}_{50}$ of BoNT/B complex by gavage followed by rescue with $12.4 \mu \mathrm{g}$ of Combo mAbs by IV at $8,10,12 \mathrm{~h}$ post-intoxication were plotted over time. Control mice were injected with PBS IV at $6 \mathrm{~h}$ post-intoxication instead of Combo mAbs.

Orally-ingested BoNT/B would have to reach the blood stream or lymph to cause disease, thus one can predict the timing of when toxins reach those destinations by when protective antibodies cease to protect animals from intoxication. The timing of protection suggests that BoNT/B likely reaches the bloodstream at about $10 \mathrm{~h}$ after oral ingestion of BoNT/B complex. This is in sharp contrast to the much shorter oral protection window exhibited by $\mathrm{mAb}$ Combos against BoNT/A with BoNT/A complex transit through the intestinal tract and exit into the bloodstream estimated at about $7 \mathrm{~h}$ after oral ingestion [10,22,30]. The time between ingestion of toxin to the detection of BoNTs in the blood stream represented the time for toxin transit through the stomach, the intestinal tract, and receptor-mediated translocation through the intestinal epithelial cells into the blood stream and/or lymph [10]. Thus, it appears that the BoNT/B complex protected toxin better from intestinal degradation [31] but also slowed intestinal tract transit when compared with BoNT/A complex. It is not clear yet whether complex size or unique properties of the BoNT/B NAPs contributed to the increased toxicity of BoNT/B complex. Once orally-ingested BoNT reaches the blood stream, it would be quickly absorbed, following the systemic biologic half-life pattern (Figure 2). For both systemic and oral mouse antibody neutralization models, no mAb rescue was observed when mAbs were administered after visible symptoms of botulism (such as slowness, limping, etc.) became apparent.

\subsection{Monoclonal Antibodies do not Inhibit BoNT/B Catalytic Activity}

MAbs can potentially neutralize BoNTs by blocking the endopeptidase activity of the BoNT Lc or by opsonization and clearance of antibody-toxin complex from the blood stream by immune cell processes [2,32-34]. Our mAbs bind to the Hc domain of BoNT/B and, thus, should not inhibit the catalytic activity of the toxin. However, this does not rule out that a combination of mAbs would not have such an effect. To test whether our individual or Combo mAbs-inhibited catalytic activity, we compared the cleavage of a recombinant GstSynaptobrevin II protein in the presence or absence of mAbs and the BoNT/B Lc. BoNT/B Lc cleaved the C-terminal of GstSynaptobrevin II substrate to yield a smaller protein that is visible in Western blots visualized with a HRP-labeled anti-Gst antibody. Control reactions with no mAbs present yielded a 77\% cleavage of the full length protein (Figure 6). Addition of individual mAbs MCS6-27, BoB92-23, or BoB92-32, or the Combo mAbs did not inhibit the endopeptidase activity of BoNT/B Lc. In the absence of BoNT/B Lc, the presence of mAbs did not yield any cleavage of the GstSynaptobrevin II. This result suggests that the Combo mAbs are likely 
blocking toxin neuronal entry via steric hindrance, or by toxin clearance via opsonization through the liver or other immune organs, although, we cannot rule out that binding of three mAbs could cause a rare conformation change that leads to Lc activity inhibition.

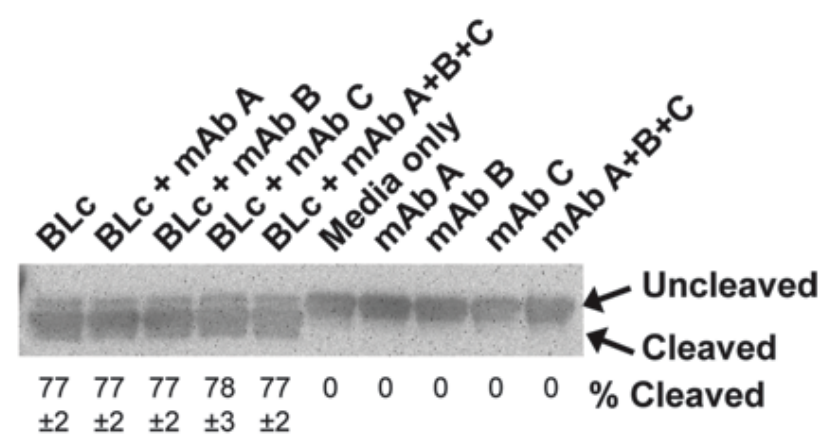

Figure 6. Individual or combination of mAbs does not inhibit BoNT/B endopeptidase activity. Endoprotease activity of the BoNT/B light chain (Lc) was measured by determining the percentage of cleavage of GstSynaptobrevin II after treatment with $2.5 \mu \mathrm{g}$ of individual or Combo mAbs. Control reactions substituted Lc with buffer or by addition of buffer instead of mAbs. Percentage of cleaved GstSynaptobrevin II was determined for reactions with a visible cleavage fragment (mean \pm S.E.M., $n=3)$.

\section{Experimental Section}

\subsection{Reagents}

Purified holotoxin and complex BoNT/B (Okra strain) were purchased from Metabiologics Inc. (Madison, WI, USA) and stored at $4{ }^{\circ} \mathrm{C}$ and $-20{ }^{\circ} \mathrm{C}$, respectively. Chemicals and reagents were generally purchased from Fisher Scientific (Walthe, MA, USA) or Sigma-Aldrich (Saint Louis, MO, USA) unless otherwise indicated. Toxin samples were diluted 1:100 in phosphate-gelatin buffer $\left(0.028 \mathrm{M}\right.$ sodium phosphate, $\mathrm{pH} 6.2,0.2 \%$ gelatin) and stored at $-80{ }^{\circ} \mathrm{C}$ before use. Rabbit anti-BoNT/B antibody was purchased from Metabiologics and stored at $4{ }^{\circ} \mathrm{C}$. Gst-Synaptobrevin-II substrate and BoNT/B light chain were purchased from List Biological Laboratories (Campbell, CA, USA). MAbs used were MCS6-27, BoB92-23-23-7 (or BoB92-23 in short), and BoB92-32-1-10 (or BoB92-32 in short) [19-21] toxins. Antibodies were purified from mouse ascite fluids by protein G-affinity chromatography. Purified antibodies were diluted in PBS, pH 7.4 and stored at $-80{ }^{\circ} \mathrm{C}$ until use. Female Swiss Webster, 4-5 week old, mice were purchased from Charles River Laboratories (Portage, MI, USA).

\subsection{Electrochemiluminescence (ECL) Immunoassay for the Detection of BoNT/B}

MA2400 96-Well standard ECL plates (Meso Scale Discovery or MSD, Gaitherburg, MD, USA) were treated with $30 \mu \mathrm{L} /$ well of a $2 \mu \mathrm{g} / \mathrm{mL}$ solution of anti-BoNT/B specific mAb MCS-6-27 in PBS and $0.05 \mathrm{M}$ carbonate-bicarbonate buffer $\mathrm{pH} 9.6$ and stored in $4{ }^{\circ} \mathrm{C}$ until use. Plates were blocked with $200 \mu \mathrm{L} /$ well of Tris-Buffered Saline pH 8.0 (TBS: $0.05 \mathrm{M}$ Tris, $0.138 \mathrm{M} \mathrm{NaCl}, 0.027 \mathrm{M} \mathrm{KCl}$ ), $0.05 \%$ Tween-20 and $3 \%$ nonfat milk (TBS-T-NFM) for $1 \mathrm{~h}$ with shaking at $37^{\circ} \mathrm{C}$. Next, $30 \mu \mathrm{L} /$ well of BoNT/B standards (ranging from 10,000 to $0.64 \mathrm{pg} / \mathrm{mL}$ ) in TBS-T-NFM as well as serum samples (diluted $50 \%$ serum to buffer), were added and the microassay plates incubated at $37^{\circ} \mathrm{C}$ with shaking for $1 \mathrm{~h}$. Plates were then washed $3 \times$ with TBS-T buffer. For BoNT/B detection, $30 \mu \mathrm{L} /$ well of a $2 \mu \mathrm{g} / \mathrm{mL}$ solution of biotinylated BoB92-32 was added to the wells. The plates were then incubated at $37^{\circ} \mathrm{C}$ for $1 \mathrm{~h}$, washed $3 \times$ in TBS-T $\mu \mathrm{L}$. The plates were then incubated at $37^{\circ} \mathrm{C}$ for $1 \mathrm{~h}$, washed $3 \times$ in TBS-T. A $30 \mu \mathrm{L} /$ well of a 1:1000 dilution of a ruthenium-conjugated SULFO-TAG ${ }^{\mathrm{TM}}$ Streptavidin (MSD) was then added and the plates incubated for $1 \mathrm{~h}$ at $37{ }^{\circ} \mathrm{C}$ with shaking followed with 
$3 \times$ washes with TBS-T buffer and the addition of $200 \mu \mathrm{L} /$ well of $1 \times$ Read Buffer T with surfactant (MSD) before reading with a Sector Imager 2400 (MSD). Rabbit anti-BoNT/B polyclonal antibodies were also used instead of BoB92-32. Following incubation with $2 \mu \mathrm{g} / \mathrm{mL}$ rabbit antibodies, the assay plate is then incubated with a biotinylated goat anti-rabbit antibody, followed by addition of a ruthenium-conjugated SULFO-TAG ${ }^{\mathrm{TM}}$ Streptavidin. The amount of toxin present in sera was determined by comparison to the toxin standards in TBS-T-NFM included on each plate and by comparing the unknown signal to that of the buffer standard using the MSD Discovery Workbench software program (MSD). Each plate contained standards and samples in duplicate wells. The statistical significance of the ECL assays was determined using the Prism 6 program. LOD was determined by with standard equations in the Discovery Workbench software program. The LODs were reported as mean plus the standard error of the mean (SEM, $n \geqslant 4$ ). Results from a typical standard curve for BoNT/B is shown in Figure 1A.

\subsection{Mouse Intoxication and Neutralization Models}

For the mouse systemic model, random groups of at least 10 mice were injected intravenously (IV) into the lateral tail vein with $100 \mu \mathrm{L}$ of $10,000 \mathrm{pg} / \mathrm{mL}$ of BoNT/B holotoxin in phosphate gelatin buffer. $1000 \mathrm{pg} /$ mouse is equivalent to about 80 intraperitoneal (IP) mouse $\mathrm{LD}_{50}$. In the oral model, 10 mice were treated with $0.06 \mu \mathrm{g}$ each, equivalent to three mouse oral $\mathrm{LD}_{50}$, in $100 \mu \mathrm{L}$ BoNT/B complex diluted in phosphate gelatin buffer via gavage using round-ended Popper needles. MAbs were diluted in sterile PBS, $100 \mu \mathrm{L}$ of antibody solution were introduced iv into mice, either prior to or post-intoxication at indicated times. Surviving mice were monitored for at least 10 days for symptoms of intoxication or death. Health statuses of mice were observed over a 21-day period. All animal use protocols described here were approved by the Animal Care and Use Committee of the USDA, Western Regional Research Center, Albany, CA, USA.

\subsection{Assay for BoNT Endopeptidase Activity}

The cleavage of the recombinant GST-Synaptobrevin-II protein substrate by the BoNT/B light chain domain was performed as suggested by the manufacturer (List Biological Laboratories Inc., Campbell, CA, USA) with minor modifications. Briefly, $10 \mu \mathrm{M}$ of GST-Synaptobrevin-II protein substrate was incubated with or without $60 \mathrm{nM}$ of BoNT/B light chain and were then were treated with $2.5 \mu \mathrm{g}$ individual $\mathrm{mAbs}$ or a combination of antibodies for $3 \mathrm{~h}$ at $37^{\circ} \mathrm{C}$ (control samples were not pre-treated with $\mathrm{mAbs}$ ) in a $10 \mu \mathrm{L}$ reaction (20 mM HEPES, $\mathrm{pH} 7.4,1.25 \mathrm{mM}$ DTT, $0.3 \mathrm{mM} \mathrm{ZnCl}{ }_{2}$ and $0.2 \%$ Tween-20). The reaction was then stopped by the addition of $4 \times$ LDS buffer (Invitrogen, Carlsbad, CA, USA) to give a final concentration of $1 \times$, followed by heat inactivation $\left(90{ }^{\circ} \mathrm{C}\right.$ for $10 \mathrm{~min}$ ). Products were then separated on SDS polyacrylamide gel electrophoresis (PAGE) using NuPAGE, 10\% Bis-Tris gels (Invitrogen) followed by Coomassie blue staining or Western blotting. For Western blots, cleaved or un-cleaved recombinant GST-Synaptobrevin-II protein substrate was visualized by staining with a primary goat anti-Gst antibody (GE Healthcare city, Pittsburg, PA, USA) diluted 1:5000 in TBS-T and 5\% milk buffer, followed by a secondary rabbit anti-Goat IgG peroxidase conjugated (Pierce). Stained gels and Western blots were analyzed with a FlurChem SP AlphaImager (Alpha Inotech, San Leandro, CA, USA). Molecular weight standards were purchased from Invitrogen. Statistical significance of data collected from five separate experiments was determined with unpaired $t$-tests using the Prism 6 statistics software (GraphPad Software Inc., San Diego, CA, USA).

\section{Conclusions}

This study aims to address two important areas of interest in the treatment of botulism: sensitive and timely detection of BoNTs and antibody-based therapies. As shown in the mouse models of systemic and oral toxin challenges and actual botulism cases, early delivery of neutralizing antibodies is imperative for rapid recovery from disease and decreased hospitalization times. We have 
developed an improved ECL assay for BoNT/B that has detection sensitivity of $1 \mathrm{pg} / \mathrm{mL}$, more sensitive, less time consuming, and required less sample volumes than the current standard mouse bioassays. We have also tested the use of monoclonal antibodies in the neutralization of BoNT/B after both systemic and oral challenges in the mouse model. Small amounts of a combination of these mAbs protected mice from botulism. These antibodies could, in the future, be humanized and used as therapeutic antibodies. Currently, humanized anti-BoNT antibodies are being tested for use as therapeutics $[35,36]$ and human antibodies purified from BoNT-immunized volunteers have been used successfully to combat botulism in infants [14,15]. Increasingly sensitive methods for toxin detection will allow quick diagnosis of disease and better knowledge and availability of BoNT neutralizing antibodies will help move us toward the design of more efficacious treatment for botulism.

Acknowledgments: The authors would like to acknowledge Christina Tam, Reuven Rassooly and Wallace Yokoyama for critical review of this manuscript; Wanless Hatcher and Zeke Martinez for their help with animal care and handling. This work was funded by the United States Department of Agriculture, Agricultural Research Service, National Program project NP108, CRIS 5325-42000-048-00D. L.W.C. was also funded by the National Institute of Allergy And Infectious Diseases Service Grant U54 AI065359 and L.H.S. was also funded by interagency agreement IAA\#40768 with the Department of Homeland Security.

Author Contributions: Luisa W. Cheng and Larry H. Stanker conceived and designed the experiments; Luisa W. Cheng, Thomas D. Henderson II and Tina I. Lam performed experiments and analyzed the data; Luisa W. Cheng and Larry H. Stanker contributed reagents/materials/analysis tools; Luisa W. Cheng and Tina I. Lam wrote the paper.

Conflicts of Interest: The authors declare no conflict of interest.

\section{References}

1. Arnon, S.S.; Schechter, R.; Inglesby, T.V.; Henderson, D.A.; Bartlett, J.G.; Ascher, M.S.; Eitzen, E.; Fine, A.D.; Hauer, J.; Layton, M.; et al. Botulinum toxin as a biological weapon: Medical and public health management. JAMA 2001, 285, 1059-1070. [CrossRef] [PubMed]

2. Simpson, L.L. Balancing the benefits and risks of a botulinum toxin vaccine. Expert Rev. Vaccines 2007, 6, 883-886. [CrossRef] [PubMed]

3. Rossetto, O.; Pirazzini, M.; Montecucco, C. Botulinum neurotoxins: Genetic, structural and mechanistic insights. Nat. Rev. Microbiol. 2014, 12, 535-549. [CrossRef] [PubMed]

4. Singh, B.R. Intimate details of the most poisonous poison. Nat. Struct. Biol. 2000, 7, 617-619. [CrossRef] [PubMed]

5. Simpson, L.L. Identification of the major steps in botulinum toxin action. Annu. Rev. Pharmacol. Toxicol. 2004, 44, 167-193. [CrossRef] [PubMed]

6. Poulain, B.; Poppoff, M.R.; Molgo, J. How do the botulinum neurotoxins block neurotransmitter release: From botulism to the molecular mechanism of action. Botulinum J. 2008, 1, 14-87. [CrossRef]

7. Chen, S.; Hall, C.; Barbieri, J.T. Substrate recognition of VAMP-2 by botulinum neurotoxin B and tetanus neurotoxin. J. Biol. Chem. 2008, 283, 21153-21159. [CrossRef] [PubMed]

8. Shone, C.C.; Hambleton, P.; Melling, J. A 50-kDa fragment from the NH2-terminus of the heavy subunit of Clostridium botulinum type A neurotoxin forms channels in lipid vesicles. Eur. J. Biochem. 1987, 167, 175-180. [CrossRef] [PubMed]

9. Oguma, K.; Fujinaga, Y.; Inoue, K. Structure and function of Clostridium botulinum toxins. Microbiol. Immunol. 1995, 39, 161-168. [CrossRef] [PubMed]

10. Lam, T.I.; Stanker, L.H.; Lee, K.; Jin, R.; Cheng, L.W. Translocation of botulinum neurotoxin serotype A and associated proteins across the intestinal epithelia. Cell Microbiol. 2015, 17, 1133-1143. [CrossRef] [PubMed]

11. Ohishi, I.; Sugii, S.; Sakaguchi, G. Oral toxicities of Clostridium botulinum toxins in response to molecular size. Infect. Immun. 1977, 16, 107-109. [PubMed]

12. Baldwin, M.R.; Tepp, W.H.; Przedpelski, A.; Pier, C.L.; Bradshaw, M.; Johnson, E.A.; Barbieri, J.T. Subunit vaccine against the seven serotypes of botulism. Infect. Immun. 2008, 76, 1314-1318. [CrossRef] [PubMed]

13. Cai, S.; Singh, B.R.; Sharma, S. Botulism diagnostics: From clinical symptoms to in vitro assays. Crit. Rev. Microbiol. 2007, 33, 109-125. [CrossRef] [PubMed] 
14. Tacket, C.O.; Shandera, W.X.; Mann, J.M.; Hargrett, N.T.; Blake, P.A. Equine antitoxin use and other factors that predict outcome in type A foodborne botulism. Am. J. Med. 1984, 76, 794-798. [CrossRef]

15. Dezfulian, M.; Hatheway, C.L.; Yolken, R.H.; Bartlett, J.G. Enzyme-linked immunosorbent assay for detection of Clostridium botulinum type A and type B toxins in stool samples of infants with botulism. J. Clin. Microbiol. 1984, 20, 379-383. [PubMed]

16. Sharma, S.K.; Ferreira, J.L.; Eblen, B.S.; Whiting, R.C. Detection of type A, B, E, and F Clostridium botulinum neurotoxins in foods by using an amplified enzyme-linked immunosorbent assay with digoxigenin-labeled antibodies. Appl. Environ. Microbiol. 2006, 72, 1231-1238. [CrossRef] [PubMed]

17. Ferreira, J.L. Comparison of amplified ELISA and mouse bioassay procedures for determination of botulinal toxins A, B, E, and F. J. AOAC Int. 2001, 84, 85-88. [PubMed]

18. Cheng, L.W.; Onisko, B.; Johnson, E.A.; Reader, J.R.; Griffey, S.M.; Larson, A.E.; Teppb, W.H.; Stankera, L.H.; Brandona, D.L.; Carter, J.M. Effects of purification on the bioavailability of botulinum neurotoxin type A. Toxicology 2008, 249, 123-129. [CrossRef] [PubMed]

19. Scotcher, M.C.; Cheng, L.W.; Stanker, L.H. Detection of botulinum neurotoxin serotype B at sub mouse $\mathrm{LD}(50)$ levels by a sandwich immunoassay and its application to toxin detection in milk. PLoS ONE 2010, 5, e11047. [CrossRef] [PubMed]

20. Cheng, L.W.; Stanker, L.H. Detection of botulinum neurotoxin serotypes A and B using a chemiluminescent versus electrochemiluminescent immunoassay in food and serum. J. Agric. Food Chem. 2013, 61, 755-760. [CrossRef] [PubMed]

21. Stanker, L.H.; Scotcher, M.C.; Cheng, L.; Ching, K.; McGarvey, J.; Hodge, D.; Hnasko, R. A monoclonal antibody based capture ELISA for botulinum neurotoxin serotype B: Toxin detection in food. Toxins (Basel) 2013, 5, 2212-2226. [CrossRef] [PubMed]

22. Cheng, L.W.; Stanker, L.H.; Henderson, T.D., 2nd; Lou, J.; Marks, J.D. Antibody protection against botulinum neurotoxin intoxication in mice. Infect. Immun. 2009, 77, 4305-4313. [CrossRef] [PubMed]

23. Ferreira, J.L.; Eliasberg, S.J.; Edmonds, P.; Harrison, M.A. Comparison of the mouse bioassay and enzyme-linked immunosorbent assay procedures for the detection of type A botulinal toxin in food. J. Food Prot. 2004, 67, 203-206. [PubMed]

24. Al-Saleem, F.H.; Ancharski, D.M.; Ravichandran, E.; Joshi, S.G.; Singh, A.K.; Gong, Y.; Simpson, L.L. The role of systemic handling in the pathophysiologic actions of botulinum toxin. J. Pharmacol. Exp. Ther. 2008, 326, 856-863. [CrossRef] [PubMed]

25. Dong, M.; Richards, D.A.; Goodnough, M.C.; Tepp, W.H.; Johnson, E.A.; Chapman, E.R. Synaptotagmins I and II mediate entry of botulinum neurotoxin B into cells. J. Cell Biol. 2003, 162, 1293-1303. [CrossRef] [PubMed]

26. Verderio, C.; Rossetto, O.; Grumelli, C.; Frassoni, C.; Montecucco, C.; Matteoli, M. Entering neurons: Botulinum toxins and synaptic vesicle recycling. EMBO Rep. 2006, 7, 995-999. [CrossRef] [PubMed]

27. Nowakowski, A.; Wang, C.; Powers, D.B.; Amersdorfer, P.; Smith, T.J.; Montgomery, V.A.; Sheridan, R.; Blake, R.; Smith, L.A.; Marks, J.D. Potent neutralization of botulinum neurotoxin by recombinant oligoclonal antibody. Proc. Natl. Acad. Sci. USA 2002, 99, 11346-11350. [CrossRef] [PubMed]

28. Ravichandran, E.; Gong, Y.; Al Saleem, F.H.; Ancharski, D.M.; Joshi, S.G.; Simpson, L.L. An initial assessment of the systemic pharmacokinetics of botulinum toxin. J. Pharmacol. Exp. Ther. 2006, 318, 1343-1351. [CrossRef] [PubMed]

29. Cheng, L.W.; Henderson, T.D., 2nd. Comparison of oral toxicological properties of botulinum neurotoxin serotypes A and B. Toxicon 2011, 58, 62-67. [CrossRef] [PubMed]

30. Bagramyan, K.; Kaplan, B.E.; Cheng, L.W.; Strotmeier, J.; Rummel, A.; Kalkum, M. Substrates and controls for the quantitative detection of active botulinum neurotoxin in protease-containing samples. Anal. Chem. 2013, 85, 5569-5576. [CrossRef] [PubMed]

31. Sugii, S.; Ohishi, I.; Sakaguchi, G. Correlation between oral toxicity and in vitro stability of Clostridium botulinum type A and B toxins of different molecular sizes. Infect. Immun. 1977, 16, 910-914. [PubMed]

32. Adekar, S.P.; Jones, R.M.; Elias, M.D.; Al-Saleem, F.H.; Root, M.J.; Simpson, L.L.; Scott, K. A human monoclonal antibody that binds serotype A botulinum neurotoxin. Hybridoma (Larchmt) 2008, 27, 11-17. [CrossRef] [PubMed] 
33. Fan, Y.; Geren, I.N.; Dong, J.; Lou, J.; Wen, W.; Conrad, F.; Smith, T.J.; Smith, L.A.; Ho, M.; Pires-Alves, M.; et al. Monoclonal antibodies targeting the alpha-exosite of botulinum neurotoxin serotype/A inhibit catalytic activity. PLoS ONE 2015, 10. [CrossRef] [PubMed]

34. Fan, Y.; Dong, J.; Lou, J.; Wen, W.; Conrad, F.; Geren, I.N.; Garcia-Rodriguez, C.; Smith, T.J.; Smith, L.A.; Ho, M.; et al. Monoclonal antibodies that inhibit the proteolytic activity of botulinum neurotoxin serotype/B. Toxins (Basel) 2015, 7, 3405-3423. [CrossRef] [PubMed]

35. Meng, Q.; Li, M.; Silberg, M.A.; Conrad, F.; Bettencourt, J.; To, R.; Huang, C.; Ma, J.; Meyer, K.; Shimizu, R.; et al. Domain-based assays of individual antibody concentrations in an oligoclonal combination targeting a single protein. Anal. Biochem. 2012, 421, 351-361. [CrossRef] [PubMed]

36. Meng, Q.; Garcia-Rodriguez, C.; Manzanarez, G.; Silberg, M.A.; Conrad, F.; Bettencourt, J.; Pan, X.; Breece, T.; To, R.; Li, M.; et al. Engineered domain-based assays to identify individual antibodies in oligoclonal combinations targeting the same protein. Anal. Biochem. 2012, 430, 141-150. [CrossRef] [PubMed]

(C) 2015 by the authors; licensee MDPI, Basel, Switzerland. This article is an open access article distributed under the terms and conditions of the Creative Commons by Attribution (CC-BY) license (http://creativecommons.org/licenses/by/4.0/). 